\title{
Neck muscle vibration can improve sensorimotor function in patients with neck pain
}

\author{
Konstantin Beinert, MSc ${ }^{\mathrm{a}, \mathrm{b}, *}$, Martin Keller, MSc ${ }^{\mathrm{a}}$, Wolfgang Taube, $\mathrm{PhD}^{\mathrm{a}}$ \\ ${ }^{a}$ University of Fribourg, Department of Medicine, Unit of Sports Science, Chemin du Musée 3, 1700 Fribourg, Switzerland \\ ${ }^{\mathrm{b}}$ Academy for Health Professions, Institute of Applied Science of the Human Movement System, Maximilianstraße 20, 67433 \\ Neustadt an der Weinstraße, Germany
}

Abstract

BACKGROUND CONTEXT: People with neck pain display a diminished joint position sense and disturbed postural control, which is thought to be a result of impaired somatosensory afferent activity and/or integration. Afferent processing can be artificially manipulated by vibration and was shown to reduce motor performance in healthy subjects. However, the effect of vibration on sensorimotor function in neck pain patients is scarcely investigated.

PURPOSE: To assess the effect of neck muscle vibration on joint position sense and postural control in neck pain subjects and healthy controls.

STUDY DESIGN: Case control study.

PATIENT SAMPLE: Thirteen neck pain patients and 10 healthy controls participated in the present study.

OUTCOME MEASUREMENTS: Cervical joint position sense and dynamic and static postural stability.

METHODS: Short-term, targeted neck muscle vibration with $100 \mathrm{~Hz}$ was applied after baseline measurement.

RESULTS: Vibration had opposite effects in patients and healthy subjects. Patients showed improved joint position sense $(\mathrm{p}<.01)$ and reduced dynamic postural sway $(\mathrm{p}<.05)$ after vibration, whereas vibration resulted in reduced joint position sense acuity $(p<.05)$ and a nonsignificant increase in postural sway in healthy controls.

CONCLUSIONS: This is the first study showing an improved motor performance after neck muscle vibration in patients with neck pain. Thus, vibration may be used to counteract sensorimotor impairment of the cervical spine. Potential underlying mechanisms are discussed.

\section{Introduction}

Neck pain patients demonstrate multiple sensorimotor impairments, such as reduced joint position sense [1], reduced force steadiness [2], and increased postural sway

FDA device/drug status: Not applicable.

Author disclosures: KB: Nothing to disclose. MK: Grants: Swiss Federal Institute of Sport (Magglingen, Switzerland Grant number 320030_144016) (D, Paid directly to institution). WT: Grants: Swiss National Fond (A, Paid directly to institution Grant Number 320030_144016/1).

* Corresponding author. Department of Medicine, Movement and Sport Science, University of Fribourg, Switzerland. Tel.: (41) 263-007-285; fax: (41) 263-009-771.

E-mail address: konstantin.beinert@unifr.ch (K. Beinert)
[3]. The underlying mechanisms of these impairments are not well understood, but one common feature of these sensorimotor impairments is their dependency on afferent somatosensory input of proprioceptors [4]. Recently, the interrelation between proprioceptive stimulation leading to an altered afferent input and sensorimotor performance was investigated in patients with neck pain. Muceli et al. [2] determined the effect of neck muscle vibration on cervical force steadiness and electromyographic activity. After short-term vibration, an increased cervical force steadiness and an altered electromyographic frequency band were observed. In contrast, several studies described immediate impairments of sensorimotor function because of neck muscle vibration in healthy subjects. For instance, an increased postural sway was observed during and immediately 
after neck muscle vibration [5,6]. More specifically, subjects showed increased body sway displacements toward the side opposite to the vibrated spot [6]. Furthermore, altered postural alignment in the upper cervical spine [7], a shifted perception of the body midline [8,9], and illusory movements have been reported [10]. These vibration-induced impairments are of short duration and depend on the length of application. The influence of vibration on healthy subjects is, therefore, similar to the impairments frequently observed in people with neck pain and are thought to rely on the alterations of the sensorimotor system. The phenomenon is argued to be caused by a mismatch of afferent activity provoked by vibration and the actual maintained joint position, thus, a proprioceptive disturbance [5]. In summary, studies in healthy subjects revealed negative effects of neck muscle vibration on sensorimotor function, whereas the only study which investigated neck pain patients observed a positive influence of vibration on cervical force steadiness [2]. Thus, it may be speculated that vibration affects sensorimotor function differently in healthy subjects and in neck pain patients. To clarify this point, the purpose of the present study was to examine the effects of neck muscle vibration on sensorimotor function in patients with neck pain and healthy controls. Cervical joint position sense [11] and postural control [12] are considered to rely on afferent input from the cervical spine. Therefore, these sensorimotor tasks represent good models to investigate the effects of cervical muscle vibration on sensorimotor function. Thus, the present study compared the outcomes of neck muscle vibration by assessing the accuracy of a cervical repositioning task and the stability in static and dynamic postural tasks. We hypothesized that neck muscle vibration causes impairments in cervical joint position sense and postural stability in healthy subjects but causes beneficial effects in neck pain patients.

\section{Methods}

\section{Participants}

For this case-control study, 13 subjects with chronic, recurrent neck pain and 10 healthy controls were recruited by advertisement in the local network of six physical therapy schools with over 600 students. Eligibility of participants was assessed with a structured interview and a questionnaire, which is described in more detail in the following section. The interviewer (KB) asked for the last pain episode, the frequency of episodes in a month, and the total amount of episodes in 1 year with professional medical help. Furthermore, people were asked to mark the area of their neck pain on a body chart.

Subjects in the neck pain group (seven men, six women), aged 18 to 35 years (22.4 4.7 years), reported at least one episode of neck pain per month (mean 9.1 \pm 7.1 ) during the previous year with average pain intensities from 4 to 8 $(5.8 \pm 1.2)$. Patients reported idiopathic neck pain unilaterally or bilaterally, with no referral into the upper extremity. In all patients, physical examination of the cervical spine revealed positive findings such as altered joint motion and painful reactivity to palpation. Healthy control subjects were included in the control group $(21.8 \pm 3.5$ years; between 18 and 27 years) when no major neck pain episode and no medical consultation were apparent over a period of 1 year, no abnormal joint signs were observed during the physical examination, and neurologic disorders were excluded. Subjects in the control group were similar in body height and weight, age, and local distribution. Subjects were also excluded if they had undergone cervical spine surgery, reported any neurologic signs or symptoms in the upper extremity, or had participated in a neck exercise program in the past 12 months. To clearly differentiate and describe neck pain patients and healthy controls, participants completed the German version of the Neck Pain Disability Scale (NPAD-d). The German version of this questionnaire (NPAD-d) has been validated and showed excellent test-retest reliability with an intraclass coefficient (ICC) of 0.97, where Cronbach alpha varied between 0.87 and 0.97 for the different subscales [13] and revealed a mean value of $0.94[13,14]$. Highly significant correlations $(\mathrm{p}<.001)$ with criterion variables such as depression, anxiety, and health care use were found in both studies [13,14].

All participants were fully informed about the study and included after providing written informed consent. The study was approved by the local ethics committee and was conducted in accordance with the latest declaration of Helsinki.

\section{Assessments}

All subjects were tested in three different experiments (see the following section) in a random order. A rest period of 15 minutes was given between experiments to exclude the effects of fatigue and vibration on the subsequent experiment. Assessment of sensorimotor function included cervical joint position sense testing and evaluation of dynamic and static postural control. No other investigation or assessments were performed at the day of the study. The order of the tests (joint position and postural tests) was randomized between subjects, but was performed in the same order for each subject before (premeasurement) and after vibration (postmeasurement). The researcher who performed the neck muscle vibration was not blinded to the subject's condition (patient vs. healthy control) as he had to know where the vibration had to be applied (over the painful side in patients). However, the outcome assessor (MK, movement and sports scientist) was blinded to the subject's condition. All outcome measurements were performed directly after the vibration.

\section{Joint position sense}

To assess joint position sense, we used the method that was first described by Revel et al. [15], where a cervical 
goniometer (CMS,GMON, Germany) with a laser pointer (P2, NOBO, Germany) is placed on the head of the participants. Subjects were seated in an unsupported straight position on a chair with a distance of $90 \mathrm{~cm}$ to the target [15]. Care was taken that the subjects were seated so that the frontal plane was parallel to the target. The target was an adjustable board of $1.5 \times 1 \mathrm{~m}$, which was placed so that the center of the board was at eye level for each individual subject when looking straightforward. This head position was defined as the neutral head position (NHP). For testing the cervical joint position sense, subjects were instructed to move their head with blindfolded eyes from the NHP into rotation to the left and rotation to the right before relocating the head to the NHP. After assessing the NHP, eight repetitions of head relocation were performed to assess reliable data [16]. The five initial trials were used to get the subjects accustomed to the joint repositioning task. The following three repetitions were performed to measure the accuracy of joint position sense. Subsequently, another three repetitions were recorded after applying vibration to the neck muscles. The subjects indicated verbally when they thought that they had reached their NHP. The location of the laser point at that instant was marked and the deviation to the actual target position was determined in centimeters. Absolute errors were calculated. Previous studies indicated that joint position sense testing demonstrates a discriminative ability of $89 \%$, with a sensitivity of $86 \%$ and a specificity of $93 \%$ [15]. Test-retest reliability demonstrated fair-to-excellent ICCs (0.35-0.87) (for review [17]). Furthermore and most importantly, values obtained with the Revel method were shown to be highly correlated $(r=0.95)$ with ultrasound based measurements [18].

\section{Dynamic postural stability}

Postural control was evaluated using a free-swinging multiaxial device (Posturomed; Haider Bioswing, Pullenreuth, Germany). The quadratic platform on which the subjects were standing was mounted on four pendulums to guarantee free movements in the transversal plane. Platform movements were measured via a joystick potentiometer that was connected to the platform. The Posturomed was used in different recent studies $[19,20]$ and was shown to provide good test-retest reliability $(r=0.73)$ for different age groups [21]. In all postural tests, subjects were asked to minimize platform movements. To minimize the assessment of learning effects, a 5 minutes trial including perturbations and free standing was given to accustom the subjects to the device [19]. For the measurements of dynamic postural control, the platform of the device was deflected to the side ( 25 $\mathrm{mm}$ ) and was fixed magnetically (for technical details see [22]). Switching off the electromagnet resulted in a fast mediolateral $(\mathrm{ml})$ acceleration of the platform. Therefore, $\mathrm{ml}$ perturbation was unexpectedly applied by releasing the platform. Subjects were asked to reduce the $\mathrm{ml}$ platform movements during the initial 10 seconds after the perturbation, while standing on the device with the nonsupporting leg slightly bent and hands held akimbo.

After the subjects were familiar with the postural perturbation task, three trials per leg were measured as baseline values with a random order of the used leg. Participants stood in a single leg stance and were aware of the direction but not of the start of the perturbation, which was induced by the investigator at random times. After baseline measurements, 30 seconds of neck muscle vibration were applied. Immediately after vibration, a trial was recorded in single leg stance to assess vibration-induced changes in dynamic postural stability. This procedure was repeated until both legs were assessed three times. In summary, participants performed six trials on each leg. At least 2 minutes of rest were given between trials with vibration and control trials.

\section{Static postural stability}

Static postural stability was evaluated by measuring the oscillations of the center of pressure using a force plate (OR6-7 force platform; Advanced Mechanical Technology, Inc., Watertown, MA, USA). Subjects stood with closed eyes in a tandem stance on the force plate with hands held akimbo and were familiarized with the task before the measurements. The experiment started with six baseline trials of 10 seconds (three times the right foot and three times the left foot in front). Afterward, 30 seconds of neck muscle vibration was applied. Immediately after vibration, static postural stability was recorded again on the force plate in tandem stance. Three trials of 10 seconds with either the right foot in front or the left foot in front were recorded. Reliability of static postural assessment revealed good testretest reliability (ICC 0.38-0.90) [23].

\section{Intervention}

Targeted neck muscle vibration was applied in patients and healthy controls after the premeasurement incorporating the cervical repositioning task and postural stability assessments by an orthopedic manual therapist with 15 years of professional experience (KB). Vibration was applied via a handheld vibration device (Vibrasens; Techno Concept, France) that was already used in previous studies [7]. Neck muscles were vibrated for 30 seconds with a frequency of $100 \mathrm{~Hz}$ [5] and a linear displacement of $1 \mathrm{~mm}$ of the vibration head. The vibration head with a diameter probe of 0.5 $\mathrm{cm}$ was set horizontally on the skin directly over the targeted neck muscles with a pressure sufficient to blanch the skin [5]. Patients and control subjects were stimulated in the same way.

In patients, vibration was always applied to the painful side. In these participants, vibration was sometimes associated with discomfort or pain. If this was the case, the place of vibration was gently moved to the side. In the control group, the side of vibration was randomly chosen and kept constant for each single subject throughout the experiment. 


\section{Data analysis and statistics}

Joint position sense error was calculated for the NHP as absolute error after relocating the head from left or right rotation. Based on the results of one pilot study $(n=6)$ and previous reports of studies using the same intervention technique [2,24], we anticipated consistent treatment effects on cervical joint position sense of more than $20 \%$ points corresponding to a large effect size. Furthermore, adaptations of the cervical joint position sense were expected to head in different directions in patients and healthy controls, thus, resulting in even greater effect sizes when testing for differences between groups. Based on these considerations, a minimum of 10 subjects per group was foreseen, which is also in line with a previous study investigating the influence of neck muscle vibration on cervical force steadiness [2]. Data were averaged within and across subjects. For final calculations, data for right and left rotations were averaged to allow comparisons between groups and to identify pre- to posttest differences. Dynamic postural sway was assessed as the sum of the sway in $\mathrm{x}$ - and y-directions. For final calculation, data of the right and left leg were averaged for the evaluation of vibration-induced changes in postural stability. Static postural stability was assessed by measuring the sway of the center of pressure. To identify the influence displayed correctly of vibration between groups, repeated measures analyses of variance were conducted for NHP and dynamic and static postural stability with the within-subject factors condition (with vs. without vibration) and betweensubjects factor group (neck pain vs. control) (two [conditions] $\times$ two [groups]). In case of significant $F$ values, Bonferroni-corrected post hoc tests (Student $t$ tests) were performed to reveal group-specific changes. All variables were expressed as mean values \pm standard deviation if not indicated differently. Differences were regarded significant at $\mathrm{p}<.05$ for all tests. SPSS software 19.0 (SPSS, Chicago, IL, USA) was used for all statistical analyses.

\section{Results}

All 23 subjects completed successfully pre- and postmeasurements before and after vibration. Baseline characteristics showed no statistical significant differences in age, body height, and body weight between the neck pain and the healthy control groups. The Table presents descriptive data of the participants. Subjects with neck pain differed significantly from healthy controls in the NPAD-d (neck pain: 41.6 \pm 13.2 , control: $11.9 \pm 15.11, \mathrm{p}<.001$ ) and displayed $20 \%$ activity limitations, characterized as mild neck pain; healthy controls subjects demonstrated no restrictions. Before vibration, neck pain patients revealed significantly larger deviations from the NHP than the healthy controls $(16.1 \pm 6.3$ $\mathrm{cm}$ vs. $7.7 \pm 3.1 \mathrm{~cm} ; \mathrm{p}<.001)$. In contrast, no significant differences in platform sway were found at baseline measurements between neck pain patients and healthy controls in the dynamic perturbation task (sway path: $38.5 \pm 18.7 \mathrm{~cm}$
Table

Baseline demographic and clinical characteristics of participants

\begin{tabular}{llll}
\hline & Neck pain patient & \multicolumn{2}{l}{ Healthy control } \\
Characteristics & $\mathrm{n}=13$ & $\mathrm{n}=10$ & $\mathrm{p}$ \\
\hline Age (y) & $22.4 \pm 2.7$ & $21.8 \pm 3.5$ & .98 \\
Body height (cm) & $178 \pm 9$ & $177 \pm 7$ & .38 \\
Weight (Kg) & $74 \pm 10$ & $72 \pm 9$ & .11 \\
Pain episodes (mo) & $9.1 \pm 7.1$ & $0.4 \pm 0.5$ & .00 \\
Neck pain intensity (NRS 0-5) & $2.92 \pm 0.6$ & $0.9 \pm 1.2$ & .00 \\
NPAD-d (100) & $41.6 \pm 13.2$ & $11.9 \pm 15.11$ & .00 \\
\hline
\end{tabular}

Note: Mean and standard deviations are shown.

NRS, Numeric rating scale; NPAD-d, Neck pain and disability scale German version.

vs. $36.8 \pm 23.4 \mathrm{~cm} ; \mathrm{p}=.83)$ and the static tandem stance $(39.8 \pm 15.2 \mathrm{~cm}$ vs. $38.0 \pm 4.6 \mathrm{~cm} ; \mathrm{p}=.18)$.

\section{Joint position sense}

The sensorimotor response for relocation of the neutral head position after 30 seconds of unilateral neck muscle vibration resulted in a significant time $\times$ group effect (time pre/ postmeasurement $\times$ group $_{\text {neck }}$ pain/control $(\mathrm{NP} / \mathrm{Con}): \mathrm{F}_{1 ; 22}=23.58$; $\mathrm{p}<.001)$. After vibration, subjects with neck pain demonstrated an improved joint position sense indicated by a reduction in the repositioning error (previbration: mean: $16.1 \pm 6.3 \mathrm{~cm}$; range: $7.7-35.4 \mathrm{~cm}$; postvibration: mean: $12.3 \pm 4.0 \mathrm{~cm}$; range: $7.9-23.1 \mathrm{~cm} ; \mathrm{p}<.01$; Fig. 1). Healthy control subjects demonstrated a significantly decreased performance after 30 seconds of neck muscle vibration on joint

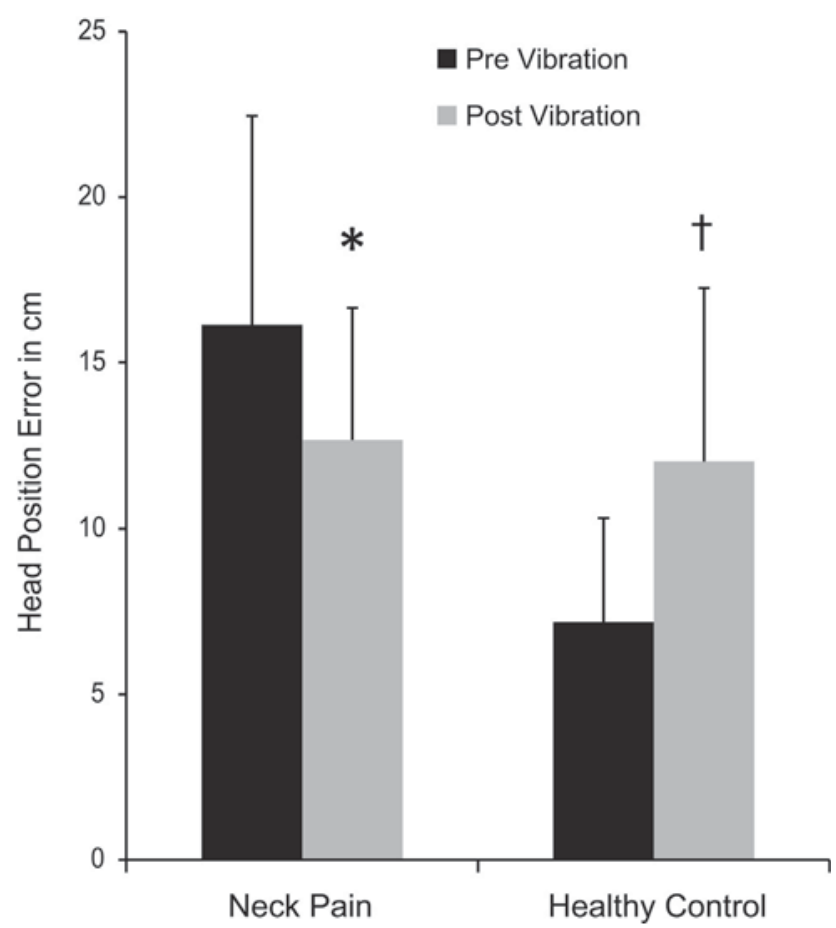

Fig. 1. Mean values for improved and decreased performance in joint position sense acuity after vibration in neck pain patients and healthy controls, respectively. Black bars represent preintervention values. Gray bars represent postintervention values. Significant differences between preand post-intervention values are marked ${ }^{*} \mathrm{p}<.001 ;{ }^{\dagger} \mathrm{p}<.05$. 
position sense acuity $(\mathrm{p}<.05)$. Joint position error increased after vibration (previbration: mean: $7.2 \pm 3.1 \mathrm{~cm}$; range: $5.0-11.3 \mathrm{~cm}$; postvibration: mean: $12.0 \pm 5.2 \mathrm{~cm}$; range: 6.2-16.0 cm; Fig. 1).

\section{Dynamic postural stability}

Targeted neck muscle vibration resulted in a significant time $\times$ group effect (time pre/postmeasurement $\times$ group $_{\mathrm{NP} / \mathrm{Con}}$ : $\mathrm{F}_{1 ; 22}=8.74 ; \mathrm{p}<.01$ ) for mediolateral induced perturbation. Post hoc analysis indicated that vibration reduced the sway path in neck pain patients (previbration: $38.5 \pm 18.7 \mathrm{~cm}$, postvibration: $29.9 \pm 11.6 \mathrm{~cm}, \mathrm{p}=.015$, Fig. 2), whereas healthy subjects showed a nonsignificant increase in sway path after vibration (previbration: $36.8 \pm 13.9 \mathrm{~cm}$, postvibration: $41.2 \pm 23.4 \mathrm{~cm}, \mathrm{p}=.5$, Fig. 2 ).

\section{Static postural stability}

There was no time $\times$ group effect (time pre/postmeasurement $\times$ group $\left._{\mathrm{NP} / \mathrm{Con}}: \mathrm{F}_{1 ; 22}=0.272 ; \mathrm{p}<.60\right)$ in static postural stability after neck muscle vibration for patients and healthy controls (Fig. 3). Neck muscle vibration had no significant effect on static postural control in neck pain patients and healthy controls. Before vibration, patients displayed an average sway path of $39.8 \pm 15.2 \mathrm{~cm}$ and displayed a sway path of $39.5 \pm 11.4 \mathrm{~cm}$ after vibration. Healthy controls demonstrated a sway path of $38.0 \pm 4.6 \mathrm{~cm}$ before vibration and $34.4 \pm 3.2 \mathrm{~cm}$ after vibration (Fig. 3 ).

\section{Discussion}

The present results demonstrate for the first time that vibration of neck muscles affects motor performance differently in healthy subjects and in subjects with neck pain.

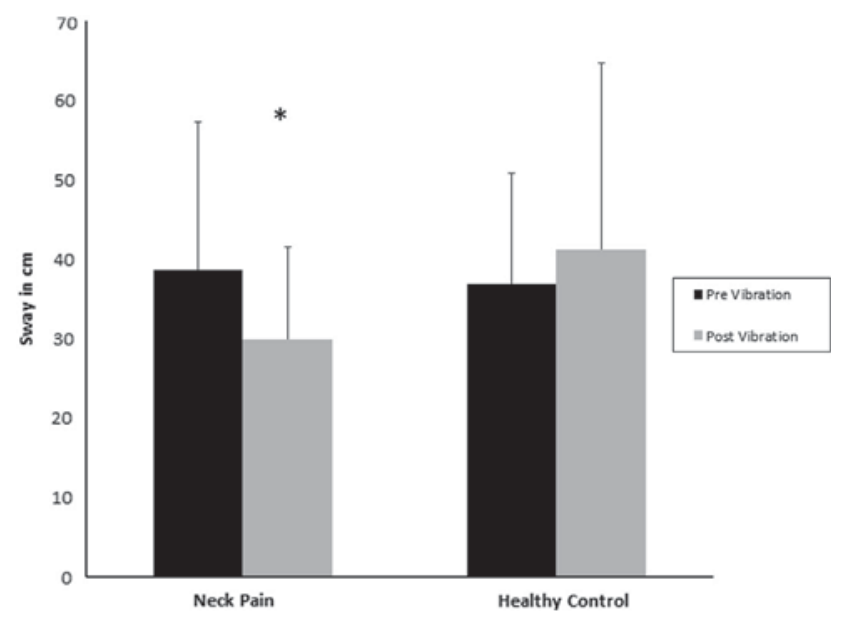

Fig. 2. Mean values for improved and decreased dynamic postural sway after mediolateral perturbation for patients and healthy controls. Black bars represent preintervention values. Gray bars represent postintervention values. Significant differences between pre- and postintervention values are marked with an asterisk $(* \mathrm{p}<.05)$.

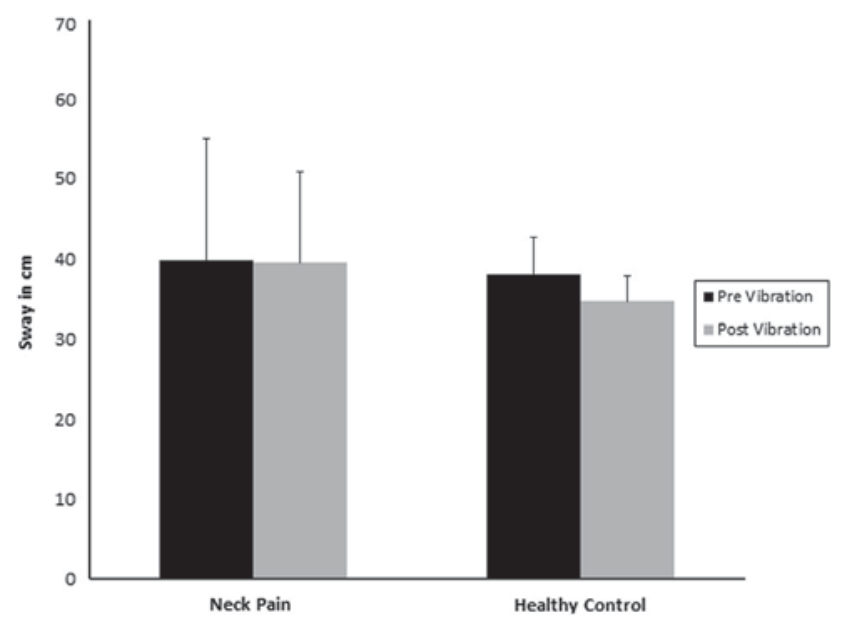

Fig. 3. Mean values for static postural sway after neck muscle vibration. Black bars represent preintervention values. Gray bars represent postintervention values.

Patients displayed significantly improved performance after vibration, whereas healthy control subjects showed a reduction in joint position sense acuity. Furthermore, dynamic postural stability was increased after vibration in neck pain patients, whereas vibration impaired postural control in healthy control subjects. Neck muscle vibration had no effect on static postural stability in neck pain patients and healthy controls.

\section{Joint position sense}

The observation in the baseline measurement of impaired sensorimotor function in neck pain patients compared with healthy controls was in line with previous studies [25]. However, our findings reveal for the first time a positive effect of neck muscle vibration on impaired joint position sense acuity in patients with neck pain. For patients, different long-term treatments have previously been shown to improve repositioning accuracy: conscious head relocation tasks [26], chiropractic care [27], and balance training [28]. All these interventions took place over a period of several weeks. In contrast, vibration in the present intervention was applied for $30 \mathrm{sec}-$ onds only before each trial. The significantly improved repositioning in the patient group indicates that proprioceptive stimulation has a great impact on the ability to perceive the location of the head in space relative to the trunk. This can also be seen in our healthy control subjects who demonstrated an immediate decrease in joint position sense acuity after neck muscle vibration. Summarized, it may be speculated that vibration in patients served to counteract their disturbed perception of their head position, whereas vibration led to an imbalanced perception in healthy control subjects.

The underlying mechanisms of our findings remain speculative but may comprise altered afferent input, altered 
central nervous system processing/integration, and/or altered motor performance:

(i) A unique feature of the cervical spine is the high density of muscle spindles $[29,30]$. Vibration to the muscles alters afferent discharge of muscle spindles [31], which in turn can affect the body perception [32]. The alterations in afferent discharge results in excitatory or inhibitory input on $\alpha$-motoneurons, depending on the duration of the applied vibration [33] and the frequency of the vibration intensity. We applied vibration of $100 \mathrm{~Hz}$ to stimulate primary afferent endings [34,35], whereas lower $(30 \mathrm{~Hz})$ and higher frequencies $(300 \mathrm{~Hz})$ have been shown to preferentially activate Meissner and Pacini corpuscles of the skin [36]. Thus, muscle vibration of $100 \mathrm{~Hz}$ seems to be able to alter afferent input via muscle spindles. In this way, the altered discharge of muscle spindles may have counteracted the potential mismatch in afferent input from the healthy and the affected side in neck pain patients. In contrast, vibration may have led to an imbalance in afferent input in healthy controls.

(ii) Alternatively, the integration and processing of afferent information may have been altered. Computational studies have suggested that the current state of a moving body is calculated based on the sensory feedback and predictions from forward models [37]. Furthermore, these studies showed that noise (uncertainty) in the sensory system leads to a reweighting of the available sensory sources [38]. Vibration increases afferent input and this additional sensory noise from primary muscle spindle endings may cause the central nervous system to rely more strongly on other sensory inputs, such as cutaneous or vestibular information. This reweighting might be beneficial for neck pain patients as they may suppress the unreliable afferent input from muscle spindles, but may be detrimental for healthy subjects who can normally rely on this information.

(iii) Besides afferent or central mechanisms, an altered motor output may have influenced the performance after neck muscle vibration. Vibration was shown to increase corticospinal excitability in the absence of actual movements, indicating that the motor system adapts in response to sensory vibration [39]. However, based on this finding, the differential adaptations in neck pain patients and healthy controls are difficult to explain.

\section{Postural control}

\section{Dynamic postural stability}

It is well established that there is a close interrelation of the cervical spine and postural control. In healthy people, increased static postural sway was observed after neck muscle vibration $[5,6,40]$. Furthermore, neck muscle fatigue results in enhanced postural sway $[41,42]$. In patients with neck pain, most studies reported impaired postural control compared with healthy control subjects $[3,43]$. The close interaction of the cervical spine and postural control is also indicated by intervention studies showing, for instance, reduced postural sway after sensorimotor training of the cervical spine [44]. Complementarily, 5 weeks of balance training resulted in a positive effect on the sensorimotor function of the cervical spine assessed by head repositioning tasks [28]. The current data obtained in the dynamic perturbation task strengthen the close interaction of sensorimotor performance of the cervical spine and postural control: in neck pain patients, vibration decreased significantly the postural sway on an unstable support surface. In healthy controls, vibration impaired, nonsignificantly, postural stability. However, further research is necessary to evaluate possible long-term effects of neck muscle vibration on dynamic postural stability and the potential benefits for rehabilitation.

\section{Static postural stability}

Neck pain patients in the present study did not show significant differences in static postural control compared with healthy control subjects, neither in the baseline values (previbration) nor after vibration. Interestingly, neck muscle vibration had no significant effect on postural sway in the neck pain group and in the healthy control group. Although some previous studies demonstrated increased postural sway in static postural tasks in neck pain patients $[3,43]$, other studies did not demonstrate significant differences between neck pain patients and healthy controls [45-47]. It may be speculated that one confounding factor is the presence or nonpresence of pain during the measurement [48]. Our participants demonstrated no or only minor pain intensities during the measurements.

The results of the healthy control group are in contrast to previous results in healthy people $[5,6]$ showing increased postural sway after neck muscle vibration. One reason for this difference might be that in our experiment, postural sway was measured after vibration, whereas in other studies, sway was assessed during vibration [5,49]. Furthermore, investigations reporting increased postural sway during neck muscle vibration reported a return to baseline values when postural control was measured a few seconds after the vibration ceased [5]. One may speculate that the duration between the end of vibration and the beginning of the measurement was too long to detect any influence of neck muscle vibration on the static balance condition in the present study. The significant effects of prior neck muscle vibration on postural control in a dynamic perturbation condition may then be explained by the task difficulty. Several studies in healthy subjects and Parkinson patients have indicated that impairments in balance control may only be detected when the task difficulty is challenging 
enough [50-52]. Thus, it may be speculated that adequate task difficulty is essential to detect (functional relevant) adaptations in postural control in response to neck muscle vibration.

\section{Limitations of the study}

The present study investigated young participants with an average age of 21.5 years. Therefore, we cannot make any conclusions for middle-aged and elderly patients as it is well known that physiologic alterations take place in the aging sensorimotor system. Furthermore, we were interested in short-term effects of neck muscle vibration and, therefore, cannot make any statements about the stability of the vibration-induced physiologic responses. Future studies should evaluate whether neck muscle vibration causes any long-term benefits for neck pain patients and identify the most effective treatment strategy (vibration duration, number of vibration series, frequency, etc.). Furthermore, the underlying physiologic mechanisms responsible for the observed effects after vibration are not identified, yet. Therefore, it is not possible to know whether these effects are specific and unique to vibration or may also be caused by other forms of physical therapy.

\section{Conclusion}

Neck muscle vibration improves joint position sense acuity of the cervical spine and ameliorates dynamic postural stability in patients with neck pain. Future studies should evaluate potential long-term benefits of neck muscle vibration.

\section{References}

[1] Armstrong B, McNair P, Taylor D. Head and neck position sense. Sports Med 2008;38:101-17.

[2] Muceli S, Farina D, Kirkesola G, Katch F, Falla D. Reduced force steadiness in women with neck pain and the effect of short term vibration. J Electromyogr Kinesiol 2011;21:283-90.

[3] Ruhe A, Fejer R, Walker B. Altered postural sway in patients suffering from non-specific neck pain and whiplash associated disorder: a systematic review of the literature. Chiropr Man Therap 2011;19:13.

[4] Gandevia SC, McCloskey DI, Burke D. Kinaesthetic signals and muscle contraction. Trends Neurosci 1992;15:62-5.

[5] Bove M, Fenoggio C, Tacchino A, Pelosin E, Schieppati M. Interaction between vision and neck proprioception in the control of stance. Neuroscience 2009;164:1601-8.

[6] Kavounoudias A, Gilhodes JC, Roll R, Roll JP. From balance regulation to body orientation: two goals for muscle proprioceptive information processing? Exp Brain Res 1999;124:80-8.

[7] Verrel J, Cuisinier R, Lindenberger U, Vuillerme N. Local and global effects of neck muscle vibration during stabilization of upright standing. Exp Brain Res 2011;210:313-24.

[8] Ceyte H, Cian C, Nougier V, Olivier I, Roux A. Effects of neck muscles vibration on the perception of the head and trunk midline position. Exp Brain Res 2006;170:136-40.

[9] Karnath HO, Reich E, Rorden C, Fetter M, Driver J. The perception of body orientation after neck-proprioceptive stimulation. Effects of time and of visual cueing. Exp Brain Res 2002;143:350-8.
[10] Taylor JL, McCloskey DI. Illusions of head and visual target displacement induced by vibration of neck muscles. Brain 1991;114(pt 2):755-9.

[11] Proske U, Gandevia SC. The proprioceptive senses: their roles in signaling body shape, body position and movement, and muscle force. Physiol Rev 2012;92:1651-97.

[12] Horak FB. Postural orientation and equilibrium: what do we need to know about neural control of balance to prevent falls? Age Ageing 2006;35(2 Suppl):ii7-11.

[13] Bremerich FH, Grob D, Dvorak J, Mannion AF. The Neck Pain and Disability Scale: cross-cultural adaptation into German and evaluation of its psychometric properties in chronic neck pain and $\mathrm{C} 1-2$ fusion patients. Spine 2008;33:1018-27.

[14] Scherer M, Blozik E, Himmel W, Laptinskaya D, Kochen MM, Herrmann-Lingen C. Psychometric properties of a German version of the neck pain and disability scale. Eur Spine J 2008;17:922-9.

[15] Revel M, Andre-Deshays C, Minguet M. Cervicocephalic kinesthetic sensibility in patients with cervical pain. Arch Phys Med Rehabil 1991;72:288-91.

[16] Pinsault N, Fleury A, Virone G, Bouvier B, Vaillant J, Vuillerme N. Test-retest reliability of cervicocephalic relocation test to neutral head position. Physiother Theory Pract 2008;24:380-91.

[17] Michiels S, De Hertogh W, Truijen S, November D, Wuyts F, Van de Heyning P. The assessment of cervical sensory motor control: a systematic review focusing on measuring methods and their clinimetric characteristics. Gait Posture 2013;38:1-7.

[18] Roren A, Mayoux-Benhamou MA, Fayad F, Poiraudeau S, Lantz D, Revel M. Comparison of visual and ultrasound based techniques to measure head repositioning in healthy and neck-pain subjects. Man Ther 2009;14:270-7.

[19] Keller M, Pfusterschmied J, Buchecker M, Muller E, Taube W. Improved postural control after slackline training is accompanied by reduced H-reflexes. Scand J Med Sci Sports 2012;22:471-7.

[20] Taube W, Gruber M, Beck S, Faist M, Gollhofer A, Schubert M. [Cortical and spinal adaptations induced by balance training: correlation between stance stability and corticospinal activation]. Acta Physiol 2007;189:347-58.

[21] Boeer J, Mueller O, Krauss I, Haupt G, Horstmann T. [Reliability of a measurement technique to characterise standing properties and to quantify balance capabilities of healthy subjects on an unstable oscillatory platform (Posturomed)]. Sportverletzung Sportschaden 2010;24:40-5.

[22] Mueller O, Günther M, Krauss I, Horstmann T. Physical characterization of the therapeutic device Posturomed as a measuring devicepresentation of a procedure to characterize balancing ability. Biomed Tech (Berl) 2004;49:56-60.

[23] Quatman-Yates CC, Lee A, Hugentobler JA, Kurowski BG, Myer GD, Riley MA. Test-retest consistency of a postural sway assessment protocol for adolescent athletes measured with a force plate. Int J Sports Phys Ther 2013;8:741-8.

[24] Harwood B, Cornett KM, Edwards DL, Brown RE, Jakobi JM. The effect of tendon vibration on motor unit activity, intermuscular coherence and force steadiness in the elbow flexors of males and females. Acta Physiol (Oxf) 2014;211:597-608.

[25] Kristjansson E, Treleaven J. Sensorimotor function and dizziness in neck pain: implications for assessment and management. J Orthop Sports Phys Ther 2009;39:364-77.

[26] Jull G, Falla D, Treleaven J, Hodges P, Vicenzino B. Retraining cervical joint position sense: the effect of two exercise regimes. J Orthop Res 2007;25:404-12.

[27] Palmgren PJ, Sandstrom PJ, Lundqvist FJ, Heikkila H. Improvement after chiropractic care in cervicocephalic kinesthetic sensibility and subjective pain intensity in patients with nontraumatic chronic neck pain. J Manipulative Physiol Ther 2006;29:100-6.

[28] Beinert K, Taube W. The effect of balance training on cervical sensorimotor function and neck pain. J Mot Behav 2013;45:271-8.

[29] Boyd-Clark LC, Briggs CA, Galea MP. Muscle spindle distribution, morphology, and density in longus colli and multifidus muscles of the cervical spine. Spine 2002;27:694-701. 
[30] Liu JX, Thornell LE, Pedrosa-Domellof F. Muscle spindles in the deep muscles of the human neck: a morphological and immunocytochemical study. J Histochem Cytochem 2003;51:175-86.

[31] Roll JP, Vedel JP, Ribot E. Alteration of proprioceptive messages induced by tendon vibration in man: a microneurographic study. Exp Brain Res 1989;76:213-22.

[32] Cordo P, Gurfinkel VS, Bevan L, Kerr GK. Proprioceptive consequences of tendon vibration during movement. J Neurophysiol 1995; 74:1675-88.

[33] Shinohara M. Effects of prolonged vibration on motor unit activity and motor performance. Med Sci Sports Exerc 2005;37:2120-5.

[34] Hagbarth KE, Vallbo AB. Afferent response to mechanical stimulation of muscle receptors in man. Acta Soc Med Ups 1967;72:102-4.

[35] Burke D, Hagbarth KE, Lofstedt L, Wallin BG. The responses of human muscle spindle endings to vibration during isometric contraction. J Physiol 1976;261:695-711.

[36] Weerakkody NS, Mahns DA, Taylor JL, Gandevia SC. Impairment of human proprioception by high-frequency cutaneous vibration. J Physiol 2007;581(pt 3):971-80.

[37] Wolpert DM, Ghahramani Z. Computational principles of movement neuroscience. Nat Neurosci 2000;3(Suppl):1212-7.

[38] Bays PM, Wolpert DM. Computational principles of sensorimotor control that minimize uncertainty and variability. J Physiol 2007;578(pt 2):387-96.

[39] Forner-Cordero A, Steyvers M, Levin O, Alaerts K, Swinnen SP. Changes in corticomotor excitability following prolonged muscle tendon vibration. Behav Brain Res 2008;190:41-9.

[40] Lekhel H, Popov K, Anastasopoulos D, Bronstein A, Bhatia K, Marsden CD, et al. Postural responses to vibration of neck muscles in patients with idiopathic torticollis. Brain 1997;120(pt 4):583-91.

[41] Schieppati M, Nardone A, Schmid M. Neck muscle fatigue affects postural control in man. Neuroscience 2003;121:277-85.

[42] Gosselin G, Rassoulian H, Brown I. Effects of neck extensor muscles fatigue on balance. Clin Biomech (Bristol, Avon) 2004;19:473-9.
[43] Silva AG, Cruz AL. Standing balance in patients with whiplashassociated neck pain and idiopathic neck pain when compared with asymptomatic participants: a systematic review. Physiother Theory Pract 2013;29:1-18.

[44] Roijezon U, Bjorklund M, Bergenheim M, Djupsjobacka M. A novel method for neck coordination exercise - a pilot study on persons with chronic non-specific neck pain. J Neuroeng Rehabil 2008;5:36.

[45] Palmgren PJ, Andreasson D, Eriksson M, Hagglund A. Cervicocephalic kinesthetic sensibility and postural balance in patients with nontraumatic chronic neck pain - a pilot study. Chiropr Osteopat 2009; 17:6.

[46] Storaci R, Manelli A, Schiavone N, Mangia L, Prigione G, Sangiorgi S. Whiplash injury and oculomotor dysfunctions: clinical-posturographic correlations. Eur Spine J 2006;15:1811-6.

[47] Madeleine P, Prietzel H, Svarrer H, Arendt-Nielsen L. Quantitative posturography in altered sensory conditions: a way to assess balance instability in patients with chronic whiplash injury. Arch Phys Med Rehabil 2004;85:432-8

[48] Nijs J, Daenen L, Cras P, Struyf F, Roussel N, Oostendorp RA. Nociception affects motor output: a review on sensory-motor interaction with focus on clinical implications. Clin J Pain 2012;28: $175-81$

[49] Bove M, Diverio M, Pozzo T, Schieppati M. Neck muscle vibration disrupts steering of locomotion. J Appl Physiol 2001;91:581-8.

[50] Taube WBD, Besemer C, Gollhofer A. The effect of inline skating on postural control in elderly people. Deutsche Zeitschrift für Sportmedizin 2010;61:45-51.

[51] Holm I, Fosdahl MA, Friis A, Risberg MA, Myklebust G, Steen H. Effect of neuromuscular training on proprioception, balance, muscle strength, and lower limb function in female team handball players. Clin J Sport Med 2004;14:88-94.

[52] Smithson F, Morris ME, Iansek R. Performance on clinical tests of balance in Parkinson's disease. Phys Ther 1998;78:577-92. 